\title{
Pseudoaneurysm complicating right ventricle-to-pulmonary artery conduit surgery: Why single-center observational studies still matter
}

\author{
Petros V. Anagnostopoulos, MD, MBA
}

From the Division of Pediatric Cardiothoracic Surgery, American Family Children's Hospital, University of Wisconsin Hospital and Clinics, Madison, Wis.

Disclosures: Author has nothing to disclose with regard to commercial support.

Received for publication Aug 18, 2017; accepted for publication Aug 18, 2017; available ahead of print Sept 26, 2017.

Address for reprints: Petros V. Anagnostopoulos, MD, MBA, Division of Pediatric Cardiothoracic Surgery, American Family Children's Hospital, University of Wisconsin Hospital and Clinics, H4/358 Clinical Sciences Center, 600 Highland Ave, Madison, WI 53792 (E-mail: petros@ surgery.wisc.edu).

J Thorac Cardiovasc Surg 2017;154:2050-1

$0022-5223 / \$ 36.00$

Copyright $(9) 2017$ by The American Association for Thoracic Surgery

http://dx.doi.org/10.1016/j.jtcvs.2017.08.043

In this issue of the Journal, Sykes and associates ${ }^{1}$ report the 20-year Boston Children's Hospital institutional experience with the development of pseudoaneurysms after right ventricle-to pulmonary artery conduit insertion. Of the 972 conduit insertions, 20 resulted in a pseudoaneurysm $(2.1 \%)$. More than half the patients with pseudoaneurysms were without symptoms, and most pseudoaneurysms were identified within 6 months from surgery. A thorough analysis, to include surgeon specific-outcomes and data on anastomotic techniques and type of suture used, revealed that patients with pseudoaneurysms were younger, were smaller, carried the diagnosis of Tetralogy of Fallot, had insertion of pulmonary homograft, had systemic or higher right ventricular pressures, and required leaving an unrestricted ventricular septal defect open. Sykes and associates ${ }^{1}$ recommended vigilant follow-up in the first few critical postoperative months, specific technical modifications in the proximal homograft-to-right ventricle anastomosis, and the avoidance of pulmonary homografts in high-risk patients.

The article by Sykes and associates ${ }^{1}$ is not only important because it provides useful insight in the risk factors for, and steps to prevent, this rare and potentially lethal complication of one of the most common congenital operations. It also demonstrates the utility of "old-fashioned" research. In the 23 years since the inception of the Society of Thoracic Surgeons Congenital Heart Surgery Database, it has become the largest congenital heart surgery registry in the world, with more than $95 \%$ of the centers in North America submitting cases and participating in data harvests every 6 months. ${ }^{2}$ With constant updates and thorough analyses, the database has defined the contemporary clinical outcome benchmarks and standards of care for a variety of lesions. At the same time, the Society of Thoracic Surgeons Congenital Heart Surgery Database has become the criterion standard platform for outcomes research and quality measurement. ${ }^{2}$ Our community recognized the shortcomings of registry databases to

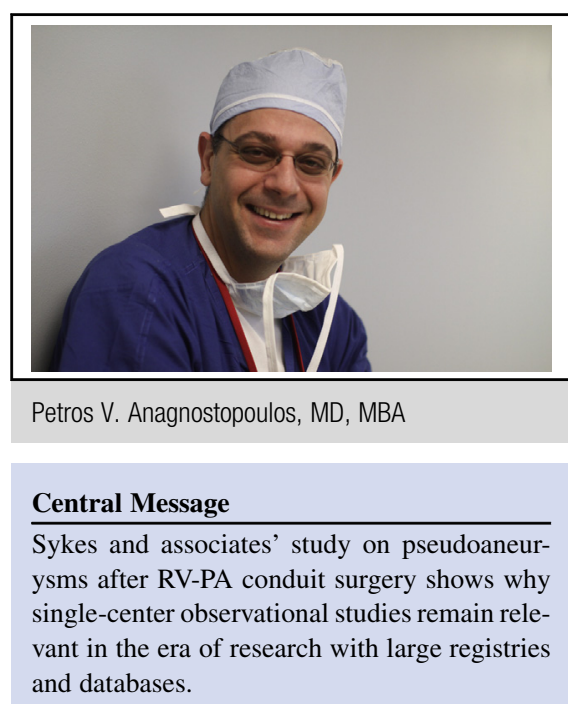

See Article page 2046. answer important clinical questions and therefore organized academic investigational databases, such as the Congenital Heart Surgeon's Society research database, with multiinstitutional comprehensive data sets for carefully selected cohorts of patients. ${ }^{3}$ To address the limitations and to bridge the knowledge gaps, projects were initiated to link the 2 databases. ${ }^{4}$ The development of powerful registries and investigational databases has revolutionized clinical research and has greatly accelerated the accumulation of new knowledge.

How can the single-center, non-randomized, retrospective study by Sykes and associates ${ }^{1}$ be relevant in the "modern research era," when such studies are often frowned upon and relegated to intermediate "levels of evidence?" 5 Such a study still matters because many of the clinical questions that surgeons have when faced with everyday problems cannot be answered without a level of granular data analysis that is difficult to find in registries and large databases. The effect of suture used or the configuration of an anastomosis, and how either affects the development of a postoperative complication will always be difficult to assess without going back to the operative report and studying the technical elements in great detail. Researchers and clinicians need to master and continue to use multiple different research methodologies to tackle the many unanswered questions in our specialty. 


\section{References}

1. Sykes MC, Nathan M, Sanders SP, Gauvreau K, Pigula FA, Rhodes J. Pseudoaneurysm complicating right ventricle-to-pulmonary artery conduit surgery: incidence and risk factors. J Thorac Cardiovasc Surg. 2017; 154:2046-9.

2. Jacobs ML, Jacobs JP, Hill KD, Hornik C, O’Brien SM, Pasquali SK, et al. The Society of Thoracic Surgeons congenital heart surgery database: 2017 update on research. Ann Thorac Surg. 2017;104:731-41.

3. Williams WG. Uses and limitations of registry and academic databases. Semin Thorac Cardiovasc Surg Pediatr Card Surg Annu. 2010;13:66-70.

4. Jacobs JP, Pasquali SK, Austin E, Gaynor JW, Backer C, Hirsch-Romano JC, et al Linking the congenital heart surgery databases of the Society of Thoracic Surgeons and the Congenital Heart Surgeons' Society: part 2-lessons learned and implications. World J Pediatr Congenit Heart Surg. 2014;5:272-82.

5. Concato J, Shah N, Horwitz RI. Randomized, controlled trials, observational studies, and the hierarchy of research designs. N Engl J Med. 2000;342:1887-92. 